\title{
Reply to the Letter to the Editor "The Postnatal Glucose Concentration Nadir Is Not Abnormal and Does Not Need to Be Treated"
}

\author{
Jeffrey R. Kaiser ${ }^{a}$ Shasha Bai ${ }^{b}$ Paul J. Rozance ${ }^{c}$ \\ a Departments of Pediatrics (Neonatal-Perinatal Medicine) and Obstetrics and Gynecology, Penn State Health \\ Children's Hospital, Penn State College of Medicine, Hershey, PA, USA; biostatistics, Department of Pediatrics, \\ Arkansas Children's Hospital, University of Arkansas for Medical Sciences, Little Rock, AR, USA; 'Department of \\ Pediatrics, Colorado School of Medicine, Aurora, CO, USA
}

\section{Dear Editor,}

We appreciate and agree with the comments by Hay et al. [1] regarding our paper, "Newborn Plasma Glucose Concentration Nadirs by Gestational-Age Group" [2]. In this study, we showed for the first time that glucose concentration nadirs for extremely low gestational age newborns (ELGANs) as well as for preterm and late preterm newborns were lower than those for full term newborns and that the time to nadir for ELGAN and preterm newborns was significantly earlier than for full term newborns.

The last sentence of the abstract was not supported by our study results, and we understand the concerns raised by Hay et al. [1] in the interpretation of the sentence: "In order to potentially prevent low glucose concentrations at the time of the nadir, exogenous glucose should be provided to all newborns as soon as possible after birth." We would like to formally retract this sentence.

Although not mentioned by Hay et al. [1], we would also like to amend the last sentence of the manuscript from "At the present time, we suggest providing exogenous glucose as soon as possible after birth and using the screening guidelines for timing and whom to screen based on AAP guidelines [29]" to the following: "At the present time, we suggest providing exogenous glucose to ELGAN and very preterm newborns as soon as possible after birth. For late preterm and term newborns, recommendations for timing and whom to screen should be based on AAP guidelines [29]."

\section{References}

1 Hay WW, Adamkin DH, Harding JE, Hawdon J: The postnatal glucose concentration nadir is not abnormal and does not need to be treated. Neonatology 2018;114:163.

-2 Kaiser JR, Bai S, Rozance PJ: Newborn plasma glucose concentration nadirs by gestationalage group. Neonatology 2018;113:353-359.

\section{KARGER}

(c) 2018 S. Karger AG, Basel

E-Mail karger@karger.com

www.karger.com/neo
Jeffrey R. Kaiser, MD, MA

Departments of Pediatrics (Neonatal-Perinatal Medicine) and Obstetrics and Gynecology, Penn State Health Children's Hospital, Penn State College of Medicine 500 University Drive, PO Box 850, Hershey, PA 17033 (USA)

E-Mail jkaiser2@pennstatehealth.psu.edu 